\title{
Ethnography, CSCW and Ethnomethodology
}

\author{
David Randall ${ }^{1,2}$, Mark Rouncefield ${ }^{3} *$ (D) \& Peter Tolmie ${ }^{1}$ \\ ${ }^{1}$ University of Siegen, Siegen, Germany; ${ }^{2}$ Linnaeus University, Växjö, Sweden; ${ }^{3}$ Lancaster \\ University, Lancaster ,UK (E-mail: m.rouncefield@lancaster.ac.uk)
}

\begin{abstract}
This paper documents some details and some examples of the influence of ethnomethodological work in the fieldwork tradition associated with European $\mathrm{CSCW}$; in particular what has been termed 'ethnomethodologically informed ethnography'. In so doing, we do not wish to downplay other perspectival and methodological contributions but to simply suggest that much of the ethnomethodological work that was done in the UK during the early development of CSCW had a distinctive character and made significant contributions to the study of complex organizational environments for design-related purposes that arguably reinvigorated the European fieldwork tradition. The distinctiveness we speak of in 'ethnomethodologically informed ethnography' had to do with what it owed to Wittgenstein and Winch as much as Garfinkel and Sacks, was rooted in a contempt for methodological fetishism, and emphasized the centrality of reasoning or rationale in the conduct of working and, more generally, social life. This focus and approach drew heavily on the ethnographic work of the likes of John Hughes in Lancaster, Wes Sharrock in Manchester, Bob Anderson at Xerox in Cambridge, and Christian Heath in King's, London, where attention was focused on the actual 'doing' of work as opposed to work in some idealised form - and it is this that we suggest has become important to design and designers of various kinds and in various domains.
\end{abstract}

Keywords: Ethnography, Ethnomethodology, CSCW, Fieldwork

\section{Introduction: ethnomethodologically informed ethnography}

Fieldwork of various sorts has long been practiced in a variety of disciplines, beginning of course with anthropology and (somewhat later) sociology. For our purposes, however, it is fieldwork in the service of some agenda that transcends the disciplinary, typically design- oriented, that is of interest. Again, we should not assume that the "turn to the social' (Grudin 1988; Hughes et al. 1992) represents the beginning, for fieldwork was actually commonplace before that. It was represented, as we pointed out some time ago (Randall et al. 2007), in areas such as cognitive work analysis (see Vicente 1999), in the Francophone ergonomics tradition, in German studies of work, in Taylorist approaches to kitchen design (see Gilbreth 1927) and in Scandinavian participatory traditions (see Bannon et al. 2011, for a review). In discussing the specific form of fieldwork that, within CSCW, is typically referred to as 'ethnography', we refer to something we consider to be distinctive and reflecting, in origin, the profound impact of 
Lucy Suchman's early work (1987). It has become commonplace to link this approach to earlier observational traditions in social anthropology (indeed we have done this ourselves (Randall et al. 2007)) and the work of people like Malinowski and RadcliffeBrown and their challenge to conventional 'strange tales of faraway people'. Such work is, of course, ongoing. It is scarcely surprising, however, that anthropological and sociological ethnographies reflect anthropological and sociological interests. Put simply, design is not a major concern for these disciplines (we do not want to make too much of a contrast here because it is evident that there is a degree of overlap, visible for instance in the work of Dourish and Bell 2011).

Regardless, our purpose in this paper is to trace the influence of ethnomethodological work in the fieldwork tradition associated with European CSCW. In so doing, we do not wish to play down other perspectival and methodological contributions for activity theory, distributed cognition, participatory design, and so on have all been influential. Our position will be that ethnomethodological work which was done in the main in the UK during that early period of CSCW had a distinctive flavor and made very significant contributions to the study of complex organizational environments for design- related purposes. Put simply, around that time, and due to a serendipitous relationship between CSCW as a burgeoning research arena and ethnomethodology as a distinctive empirical and conceptual approach (and with deference to the contribution of others), European fieldwork was reinvigorated. The distinctiveness we speak of had to do with what it owed to Wittgenstein and Winch as much as Garfinkel and Sacks, was rooted in a contempt for methodological fetishism (Berger 2002), and emphasized the centrality of reasoning or rationale in the conduct of working and, more generally, social life. Such a focus and such an approach, owes a great deal to the likes of John Hughes in Lancaster, Wes Sharrock in Manchester, Bob Anderson at Xerox in Cambridge, and Christian Heath (e.g. Heath and Luff 1992) Hence, we focus on one particular, largely UK approach to fieldwork and ethnography that has become prominent within CSCW research in Europe-,sometimes called 'ethnomethodologically informed ethnography' (EIE) but what can just as easily be called, in Heath and Luff's preferred usage, 'workplace studies'. Allied to this, and perhaps controversially, we have to admit to some doubts about what degree of coherence and continuity there is in the 'European tradition'. Some of the confusion is the result of academic assumptions about the status of method, about the epistemological status of perspectives of different kinds, of the status of 'theory' (whatever that over-used word might mean) and so on. This may be why certain kinds of rather strange understandings of what ethnomethodology might be have come to be published (e.g. Blackwell et al. 2017). We will argue here that we subscribe to no epistemology (in its proper sense of a 'theory of knowledge'), no commitment to a 'method', and a skepticism about theory (as distinguished from some kind of generalisation (of which more below)). Put simply, the ethnomethodological contribution to a European fieldwork tradition can be summed up as follows.

Firstly, the origins of the commitments we describe lie just as much in the European philosophies of Ludwig Wittgenstein, Peter Winch and Alfred Schutz as they do with the work of Garfinkel (Garfinkel 1964, 1967, 2002, 2006). In brief 
summary, this implied a careful examination of the nature of concept use and some scepticism about representational views of the mind (see e.g. Wittgenstein 2007; Harré 2017; Hacker 2012, for exegesis). It further implied that the proper business of enquiries into the social ought to be enquiry into rule-based behavior (what is often termed, 'practice' today; see Winch 2002; Schmidt 2014), and a commitment to understanding cognition as a fundamentally social matter (see Schutz, 1967). This can be seen, for example, in a range of CSCW studies concerning knowledge work, decision-making and 'organizational memory' (Randall et al. 1996, 2001, 2002). Thus, what is 'European' about the work we do lies in the philosophical traditions associated with these figures. Of course, in and of itself, that tells us little about the ethnographic work that we, and others, have undertaken. Below then, we outline the kinds of work that we, and others, have done, and the degree to which this 'fits' (or not) other conceptions of a fieldwork tradition.

Secondly, and arguably for the serendipitous reasons we mention above, it was European ethnomethodologists who gave serious attention to organizational life. In arguing this, we don't seek to underplay the achievements of, for instance, researchers at PARC in the USA, nor those of the participatory design community emanating, for the most part (at that time) from Scandinavia. Garfinkel set out an ambition in his 'studies of work' program but it was an ambition, up until that point, which was relatively unfulfilled. Relatively few studies had, at that point, concerned themselves with domains where technical knowledges were vital to the work or where whole ecologies of computer and other equipment were in play (there are a few exceptions; Mike Lynch's 'Art and Artifact in Laboratory Science' (1985) is an obvious example). As we shall see, in the late 1980s and early 1990s, some seminal studies came out of the UK in particular.

Thirdly, the perspective we rehearse is anti-method. This may seem, on the face of it, to be a strange claim but we will argue that it is best seen as a contrast to what we unoriginally call, methodological fetishism'. This cannot be over-emphasized, for there is a tendency to view ethnography as a 'method' that has consistent rules of application and hence which can lay claim to the same kinds of scientific foundations that are asserted for quantitative methods. We associate this tendency with scientistic versions of, for instance, Grounded Theory and to which, we argue, the European tradition has been largely indifferent. Peter Berger describes methodological fetishism as "the dominance of methods over content" (2002). In a similar vein, Ferrell (2009, a criminologist) argues,

"Orthodox researchers imagine that survey research and statistical analysis are somehow mystically imbued with the power of 'objectivity', that they embody the spirit of scientific inquiry, mathematical precision, and dispassionate analysis. They imagine that these methods somehow operate independently of human emotion and human action - that such methods can drain objective 'data' and useful knowledge from those who are their targets ...” (Ferrell 2009). 
Now, and unlike Berger or Ferrell (see also Burman 1997), our purpose here is not to rehearse the critique of quantitative methods in Sociology. Rather, it is to point in general to the tendency to see the validity or otherwise of qualitative approaches as, in the main, being problems of method. It is this (in our view, spurious) tendency which sees conceptual outcomes as being more valid if they have been embedded in some guarantee of consensus such as through some kind of mutual 'coding' process or, much more oddly, through notions of 'inter-rater reliability'. Such a tendency is visible, above all, in communities such as CHI, though it is increasingly evident in CSCW as well, and is associated with latter day versions of Grounded Theory and its psychologistic variant, Thematic Analysis. Reference to, and claims about, coding processes and validity by consensus have become a sine qua non for design related ethnography in the CHI community. This tendency is, at least at present, much less evident in European CSCW and we would argue that this is the result of a more eclectic and relaxed view of the 'method' associated with qualitative work. We do not, of course, credit ethnomethodology alone for this subtle difference but do want to suggest that our ongoing and systematic indifference to method is consistent with this more relaxed European view. However, our 'ethnomethodological indifference' — Garfinkel's 'naughty advice' — is a policy that has been consistently misunderstood. It refers to an indifference to the theories, policies and methods of formal analysis. Its point is, "to be indifferent to the problem of social order as it has been traditionally posed in terms of formal institutions and rules: Not to be indifferent to the problem of social order per se." (Garfinkel 2002, p. 26). Such 'ethnomethodological indifference' is a feature of the conduct of our research, often simply accomplished by immersion in the fieldwork rather than the library and any (supposedly) relevant social science literature. As Lynch (1999) suggests 'indifference' suggests a sense of detachment but this is not the same as classic notions of 'valuefreedom'. As Lynch argues:

"there is nothing heroic about indifference. It does not require an effort to purge the soul of all prejudice, or the performance of a technique that controls or rules out sources of bias. It is not a matter of freeing oneself of mentalities that are inherent in any ordinary situation; instead it is a matter of explicating such situations with a full attention to their ordinary accountability. In other words, ethnomethodological indifference is not a matter of taking something away, but of not taking up a gratuitous 'scientific' instrument: a social science model, method or scheme of rationality for observing, analyzing, and evaluationg what members already can see and describe as a matter of course." (Lynch 1999: 221)

Just as ethnomethodologically informed ethnography might claim to be 'anti-method' so too can it be characterised as 'anti-theory'. This often amounts to rather less than that phrase might seem to imply, (because it simply misinterprets Garfinkel's notion of 'indifference') but it does mean that we ask rather serious questions of any theory in terms of what analytic work it claims to do and the validity of those claims. Unlike theoretical approaches that claim to reveal the unknown or the 
counterintuitive, ethnomethodology, says the kinds of things that members couldn't disagree with, it simply reminds them of things they already know and recognise as normal, ordinary, and natural. While theory aspires to novelty, to suggest that society or organizations are actually different to how people believe they are or experience them, this emphasis, this agenda, means that members' experiences get left out and disregarded. The phenomena of everyday life in whatever domain are hidden as somehow being 'surplus to requirements'. When everyday experiences are included it is generally only from within some theoretical schema. As we have consistently argued elsewhere (Rouncefield and Tolmie 2016; Tolmie and Rouncefield 2016) it seems as if people live the lives they do in order to help some sociologist resolve some theoretical issue. Insofar as the everyday are considered, it is only from within, or through, some pre-existing theoretical framework. This seems a fairly bizarre take on everyday organizational or domestic life and so the 'anti-theory' stance of ethnomethodology is simply a resolve to look closely at phenomena without reference to what sociological theories might consider important or interesting.

A fourth, vexed, and related critique of EIE concerns the ability and desirability to 'generalise' from particular ethnographic studies. (Sharrock and Randall 2004) The problem of generalisation covers a range of related issues such as 'abstraction', 'typicality' and 'numbers as well as the insightfulness of the researcher. Is the activity and organisation studied, 'typical' of other, related or similar organisations? To what extent can the findings be generalised to other organisations? Does the study have something more general to contribute other than a massively detailed study of a single organisation at a particular time and place? A related issue is the 'numbers issue' that suggests that perhaps a single case study is an insufficient basis upon which to ground any generalisation about organisations more generally. The emphasis on numbers is related to the 'typicality' problem in that it is seen as a possible solution to the question of whether any particular situation, is unique, a 'one-off or standard, 'business as usual'. In terms of empirical generalisation and classification whilst logically there may be a need for more than one case (if indeed it can be agreed what a case is) quite how many are required is difficult to specify, without a clear sight of what the problem is, it would be difficult to go much further and determine how many more cases would be sufficient - one, two, forty-two? If the point of ethnomethodology is to explicate the machinery by which social action - making lending decisions, using computers, dealing with customers - 'gets done', then how often, how many times, an action occurs and is studied is, at best, marginal to whether the description of the 'machinery' is adequate or not. Further instances do not provide any more evidence, or warrantability for the description - just more, further examples. As Benson and Hughes (1991) suggest: "This is not to say that other cases, other data, are of no use, but that the number of instances, the quantity of the data, is irrelevant to the grounding of the description of the machinery' (Benson and Hughes, 1991, p. 131).

Pursuing the idea of generalization, the ethnomethodology of Harold Garfinkel made much of the notion of 'unique adequacy'. The strong version of unique adequacy demands of researchers that their analysis of settings involves only 
endogenous features of those settings. Put simply, it entails a complete indifference to theoretical assumptions about work done in those settings. The weak version of unique adequacy (which is predicated on the notion of 'vulgar competence') has to do with the way in which this endogenous understanding might be acquired. Hence Garfinkel:

“... stressed the notion of 'vulgar competence' in his explication of what ethnomethodology might be and how ethnomethodologists might conduct themselves for the purposes of enquiry. 'Vulgar competence' here might mean more than one thing but most certainly points to, at the very least, a certain attention to 'how the job gets done' and what might be necessary, in terms of skilful, or artful, performance in order that this happens. At a minimum, this would suggest that 'vulgar competence' would entail the recognition of skill or competence in such a way that one could grasp what it means to be 'good' at a job of work. For the most part we can treat the notion of 'vulgar competence' as an ambition, one which ethnomethodologists would hold to such that they can aspire, for instance, to the conversation with people who competently perform job functions that would go, 'yes, you really do understand what it is we do'." (Sharrock and Randall 2016),

In our view, the production of valid and useful ethnographic accounts relies initially on some satisfaction of the unique adequacy requirement. This insists that the researcher develops a vulgar competence in the setting itself, in order to understand life as practitioners themselves comprehend and practice it and to be able to describe in the language of the setting. As Garfinkel and Weider (1992) put it:" for analysts to recognize, or identify, or follow the development of, or describe phenomena of order in local production of coherent detail the analyst must be vulgarly competent in the local production and reflexively natural accountability of the phenomena of order he [or she] is 'studying"'. (Garfinkel and Wieder 1992, p. 182). As Crabtree (2001) suggests the issue is one of 'probativeness' (Garfinkel and Wieder 1992) of descriptive adequacy, which requires some mundane competence in the practices of the domain such that the researcher can deliver an account that is intelligible to competent members. Such arcane matters as the difference between 'weak' and 'strong' unique adequacy may raise a puzzled eyebrow on the part of some readers, but there are good reasons, in the context of CSCW, for thinking carefully about the difference. An ambition for ethnomethodologists is to gain the best possible understanding of deployed skills that they can. Of course, doing the job yourself constitutes the ideal method for doing this. Unfortunately, that remains an ideal in many circumstances. For reasons of training, legality, etc. it is often simply not possible for the ethnographer to become a 'competent member' in some organizational contexts. It has to do with the good practical reason that investigating organizational contexts such as a bank entails investigation of many different work roles, many different sets of skills and, indeed, many different 'settings' in the domain in question. It is quite simply, then, not possible for hybrid studies, of the kind that Garfinkel was interested in, to be 
done. In relation to generalization, it would be something of a surprise to discover than no two people ever do the same thing in the same way. That would make social life pretty much impossible, since we would be unable to recognize what the 'same thing' was (as Winch pointed out). Having said that, and a major reason for at least being competent enough to recognize what it means to be good at something, one of the key insights that ethnomethodologists from Suchman onwards (in CSCW) have provided, is that the social distribution of expertise - how things actually get done, how practices relate to rules and procedures and who is good at what they do is significant.

\section{The business of ethnography}

There is not really too much disagreement about what ethnographers of almost any persuasion actually do. Most researchers agree that the ethnographer's primary job is to shut up and listen, to watch what happens, see what people do, to write it down, tape it, record what documents can be recorded, and so on. The sorts of things that can be collected and recorded include: conversations, descriptions of activities, diagrams of places, job descriptions, memos, notices, graffiti, transcripts of meetings, 'war stories', 'water-cooler talk' and more. It is not that such materials are likely to be hard to find or necessarily have any particular intrinsic value; the material is valuable insofar as it can be made relevant or useful for what it can say about the social organization of activities (and how this may in some fashion be relevant to design). The hardest task for any ethnographer, especially those new to fieldwork, is to analyse this mass of material, to find out what it all amounts to and what 'implications for design' (Dourish 2006, 2007) might spring from these observations. However, and despite this (perhaps unusual) general agreement, ethnography is not a unitary approach to data collection and analysis but is instead a convenient gloss on various and different sensitivities and analytic frameworks. Here we are primarily concerned with documenting what might be termed the sensitivities and 'analytic purchases' which, we feel, have been influential in Europe above all. While any ethnographic stance generally entails some minimum orientation, of viewing the social world from the standpoint of its participants, the ethnomethodological approach we have promoted is predicated on the examination of what people are doing in the contexts they find themselves in, and their reasons for doing things in that fashion. In emphasizing 'reasons', of course, we demonstrate an indifference to various kinds of causal explanation. For our ethnographic enquiries, members and their subjective orientations and experiences are central and the approach focuses on the places and circumstances where meanings and courses of action are constructed, maintained, used and negotiated; in brief, 'how people do what they do and what reasons do they have for doing it that way?" In passing, we might note that the term, 'member' also seems to generate some confusion. We can reasonably assume that people interacting in various contexts have some degree of interactional competence. In work environments, of course, it is likely that these competencies consist in some 
technical knowledges and skills; the use of technologies; familiarity with organizational features of one kind or another, and so on. It is worth pointing out that this kind of assumption is necessary for any understanding of the interactional basis of the social world, and that it contains no implications whatsoever for the accuracy or otherwise of our knowledge about the wider world. It in no way implies that people are faultless in their behavior. It contains no presumptions about 'intelligence' or stupidity (in contrast to the bizarre and wholly incorrect picture of ethnomethodology given by Blackwell et al). It simply means that, as Wittgenstein put it, that we know (most of the time) how to 'go on'. Exactly how we 'go on' in the contexts with which we are familiar, in the version we subscribe to, is the proper topic of ethnographic enquiry.

\section{Ethnomethodology and ethnographic analysis}

We pointed out in our introduction that, although ethnographic studies can be traced back to the anthropologies of the 1920s and onwards (notably those of Malinowski 2013; Radcliffe-Brown 1922/2013; and so on.), our interests and concerns are a long way from the functionalist challenges to evolutionary thinking that dominated at that time. In passing, however, we should note that anthropological thinking has not disappeared from the CSCW canon and many of the disputes that are evident about the proper role of ethnographic work reflect this (again in passing, because it is often forgotten, we might note that Malinowski was one of the first people to recognize that norms and actions are very different things). It is not, however, our topic here. We will, instead, briefly describe what we call, rather pretentiously, 'precepts' here. As Randall (2018) puts it,

"Roughly speaking, this entails a commitment to the point of view of the actor; some kind of preference for study of the way actors order their activities; an interest in the skills, competencies and 'artfulness' that actors bring to their efforts, and an interest in the use of artefacts. It presupposes no particular data collection techniques (we should remind ourselves that the classic anthropologists had no recourse to the recording methods we possess today and seldom bothered themselves with anything resembling, for instance, a transcript), no rules concerning time taken and no uncontested position concerning truth and objectivity."

These 'precepts' are nothing more than broad recommendations as to what kind of thing one might pay attention to when doing an ethnography for design-related purposes. Again, there is no suggestion here that only ethnomethodologists have been concerned with these analytic tropes, for that would be simply wrong. Nevertheless, they have proven to be useful 'aids to a sluggish imagination', providing some practical advice on what the ethnographer might usefully pay attention to. They begin with the idea of a 'turn to the social'. The assumption that the world is socially organized. To the average sociologists, of course, this would be no news. To 
researchers without this background, however, it is a useful sensitizing device, drawing attention to the way in which work is a great deal more than simply a matter of task completion, or cognitive load. This initial assumption leads naturally to the question of how, within any given setting, this might be done in practice. It ought to be self-evident that, for competent members, the setting and its activities are socially organized from within - by which we mean that the setting and its activities make sense to the participants. Put simply, in the normal course of events, they understand what they and their colleagues are up to. If they do not, for whatever reason, they will have recourse to methods for finding out what is going on. It is a slightly more controversial assertion, and one which distinguishes our perspective from a more cognitive approach, to argue that making sense of what members are up to involves exactly the same kind of understanding on the part of ethnographers. Controversial, that is, because various writers in the 'qualitative' tradition have asserted (see e.g. Giddens) that these are matters of interpretation, that the business of the ethnographer entails some kind of hermeneutic circle. We would argue that placing understanding at the centre of our investigations, we do not need to do any more than treat a setting in exactly the same way that members do. That is, see it in terms of the very ordinary, practical, business of getting on with things. Again, this would imply a certain attention to detail, and that detail will consist in the ways in which activities are sequenced (which often turn out to be substantially different from those mandated by organizational rules, or embedded in workflow systems), in attention to the ways in which organizational members in practice divide up their tasks in what, for them, are sensible, timely and elegant ways which facilitate getting the job done. It should not be difficult, given the attention to detail we expect, to uncover the rationales people have for doing their jobs in 'just this way'. They will have obvious concerns for determining how their activities fit into their responsibilities, their relevances, and how this will fit with that of others. It should be no surprise either, that being able to do a job of work of whatever kind involves kinds of knowledge. The knowledge can, of course, sometimes be very technical, sometimes be about the character of the organization, its rules, routines and procedures, structures of authority, and the social distribution of expertise. The point is that from the point of view of the organizational member, these are all encountered in more or less the same way- as practical exigencies that need to be dealt with.

We don't want to suggest that there is anything difficult or esoteric about this data collection process, or that it requires special social scientific training (quite the reverse). Indeed, we would like to suggest that this is what almost anybody might do, without reflection, as they go about their job of work. All the ethnographer needs to do is to shut up, watch and listen. EIE decidedly does not involve any strange initiation into any set of obscure rituals or techniques. Just as the origins of ethnography lie in a challenge to conventional, often theoretical, thinking about other cultures, and the activities of their 'members', so too there is little in the way of theorising in EIE. Nor is there much concern with issues of 'reflexivity' or 'generalization'; instead the focus is on rigour and warrantability - to be able to point at 
some piece of data to support any assertions made. Here, we might point to one divergence between the ethnographic approach we are concerned with here and the view of the more anthropologically- influenced. It is largely uncontroversial to assert that ethnography concerns itself with the 'point of view' of actors. What that point of view consists in can be understood in many different ways. It is entirely obvious that this might include reflections on moral and political issues. It should be equally evident that ethnomethodologists do not, for the most part, concern themselves with this. They simply make a different choice about analytic focus. The view of participants for the ethnomethodologist owes more to Winch than to conventional social anthropology. Instead of treating participants as essentially empty vessels into which culture and knowledge has been poured and which is then somehow displayed to researchers a more fruitful, and accurate position might be to recognise participants as researchers themselves, attempting to discover what is going on in the process of that very 'going on'. 'What is going on' becomes a problem for the 'native', for the participant, as well as the researcher and the methods by which any understanding is achieved are the focus of research; we "treat meaning as an achievable phenomenon and understanding as a risky business ..." (Sharrock and Anderson 1982, p. 135). People strive continuously to understand exactly what is going on so as to direct their actions as to 'how to go on', but such an achieved understanding is constantly open to possible challenge and revision.

The relevance of these particular precepts lies in the fact that they draw attention to the way in which orderliness can be viewed as a feature of the sensemaking procedures participants use in the course of their work. In documenting how work is socially organized, ethnographic research reveals facets of mundane organisation. The ease with which such research work is described glosses over the difficulty of its actual accomplishment, and the ease with which the researcher can sometimes (often) slip into the comfort of mere 'scenic' description (Button) or theorizing.

Ethnomethodologically informed ethnography is then the study of people who are engaged in practical action. There has been a recent reinvigoration of the term, 'practice', especially in the more recent European fieldwork tradition, and all we would want to say here is that what has been argued (by, for instance, Schmidt 2014) is quite consistent with concepts of practice which engage with routine and normativity. As ethnographers, however, is not to assert that practices consist in such things but to examine how, in the contexts we are investigating, this is done. The purpose of the ethnography is, therefore, to identify the specific activities in which participants engage to deliver some specific end, and how the character of those activities is dictated by the specificity of the circumstances. This engenders the desire to gain (fieldwork) access to the ways in which work is done in practice, and motivates the noticing of the ways in which people achieve (or fail to achieve) conduct in accord with the standardisations that they seek to implement. In advancing 'ethnomethodologically informed' ethnography, the emphasis is on 'relevance', with why this approach is particularly relevant to informing studies of work, technology and organizations for the purpose of design. 


\title{
4. Ethnomethodologically informed ethnography and its relationship to design
}

\begin{abstract}
"Systems design used to be done by a bunch of techies, deep, deep, deep within some head office building somewhere. Here they would build their system. Test it, test it, test it, until they were sure it would work, and then they would throw it over this great high brick wall, and hope the user would catch it, on the other side. Meanwhile in another part of the organisation the ethnographers were conducting their observational studies of work, layering on the detail until they were reasonably satisfied that they had adequately described the sociality of work. The study would be so heavy that they would have no need of a brick but, having given the designers ample warning to stand clear, would simply lob it over the great high brick wall with a message attached, 'read this and then build something' (Cooper et al. [1995] cited by Hughes et al., in Luff et al. [2000])
\end{abstract}

It is obvious that an ethnographic study of the kind that we have argued is typical of the recent European fieldwork tradition, consists of examining how things are done currently. This section concerns itself with trying to document and understand what ethnomethodologists and EIE have contributed to design and we suggest that any sober reflection would consider that the contribution has been considerable and worthwhile.

The complicated relationship between ethnomethodology and Design began with some fairly basic misunderstandings, when (in the beginning), ethnomethodologists were amongst the first, and for some time the only, Sociologists to make a contribution to HCI - initially through the early work of Lucy Suchman and her studies on 'plans and situated action' where she famously used her empirical work to argue against wholly cognitive approaches to an understanding of planning and decisionmaking, and through the early work of John Hughes et al. on air traffic control, perhaps producing an early, basic and fateful misunderstanding in HCI that Ethnomethodology was Sociology. Sociologists initially entered into system design through their initial work in research areas like CSCW in the period following Suchman's 'Plans and Situated Actions' and Grudin's (1988) announcement of the 'turn to the social' in system design. (and this emphasis on research and design rather than product development is also important). As it happened, and largely coincidentally (Button et al. 2015), those early sociologists generally just happened to be ethnomethodologists. ${ }^{1}$

Some of the initial forays of sociologists into design are captured in 'Sociologists can be Surprisingly Useful in Interactive Systems Design' (Sommerville et al. 1992),

\footnotetext{
${ }^{1}$ Similarly, and equally unfortunately, since much of the early work in the field incorporated various forms of ethnography as a data gathering methodology, (and, perhaps, since there is some similarity in the 'ethno' part of their name), it is perhaps clear that initially ethnomethodology and ethnography were simply confused with each other. It is also obvious that, at least to some extent this confusion continues - as seen in some of the recent responses to Crabtree et al.'s (2009) 'Ethnography Considered Harmful' paper.
} 
where Sommerville, and some fellow computer scientists, describe one of the first projects to deliberately and purposefully involve sociologists (who, as it happened, were largely but not exclusively ethnomethodologists). In the ATC project, which we refer to above, the intention was to use sociological approaches explicitly to derive software system requirements and evaluations of technology rather than simply provide some initial insights into the social circumstances of a particular setting and its impact on the usability of a system. The sociologists were expected to provide the 'big picture' and thereby bring a new perspective to design above and beyond that of the 'since it was anticipated that sociologists would uncover some subtle and 'social' features of system requirements that were unlikely to be obtained through a conventional requirements analysis process, or considered by system developers, or likely to be uncovered by some form of user-centred design. "we argue that user-centred design on its own is not enough. Rather, the design process must also take account of the social context where the computer system is installed". Apart from providing new insights into how work was accomplished the sociologists were also able to indicate the likely impact of design decisions and thereby act as 'the designer's conscience': "This effect is normally manifest as a series of questions to the sociologists of the form: "If we decide to use $\mathrm{X}$ then users will not be able to carry out action Y. Is this OK or is Y a critical action?"' (Sommerville et al. 1992, p. 6). The sociologists involved in the project either provide a simple answer to this question or, more often, highlight a wider set of issues surrounding this question". Consequently, despite being 'surprisingly useful' the study recognizes that there are also problems in collaborating with sociologists (and perhaps especially with ethnomethodologists) in particular an overestimation of the abilities of sociologists to provide simple 'answers' to the developers' questions and problems.

'Sociologists can be surprisingly useful' was a relatively optimistic assessment and was written early on in the relationship between Sociology (and Ethnomethodology) and Design when ethnographic studies, largely produced by ethnomethodologists, were unearthing some important and useful insights into the domains that were the focus for systems design and deployment. Insights that, to some extent at least mollified the designer's constant cry of 'tell me what to build'. Since then the market has become a little more crowded with a whole range of different social scientific approaches - actor-network theory (Latour 2006); distributed cognition (Rogers and Ellis 1994); activity theory (Kaptelinin and Nardi 2006); structuration theory (Jones and Karsten 2008) and so on - adopting and adapting ethnographic approaches. Indeed much of the early discussion (Plowman et al. 1995) was focused on the contribution of ethnography to design, with the focus being on the method of investigation and data collection rather than the particular approach (ethnomethodological or otherwise), taken towards analysis. But the demands and expectations of design have also changed. Whilst not quite the previous plea of 'tell me what to build' there has been a growing emphasis on understanding some of the subtleties of adapting to changes in working practice and new technology. 
Following the ATC studies, Hughes et al. subsequently published an influential paper, called 'Moving Out of the Control Room', in which some different uses of ethnography as a method in design were distinguished. The different uses of ethnography that Hughes et al. (1994) identify include:-.

- Concurrent ethnography: where design is influenced by an on-going ethnographic study taking place at the same time as systems development.

- Quick and dirty ethnography: where brief ethnographic studies are undertaken to provide a general but informed sense of the setting for designers.

- Evaluative ethnography: where an ethnographic study is undertaken to verify or validate a set of already formulated design decisions.

- Re-examination of previous studies: where previous studies are re-examined to inform initial design thinking.

The paper was very influential, especially insofar as it seemed to justify a shorter version of ethnographic work or, more properly, did not imply any close relationship with the production of 'requirements'. Instead, the 'quick and dirty' could be thought of as doing 'scoping' work, identifying with a broad brush what the main features of work activities looked like, what skills could be identified and how, in outline, this might relate to the problem of design. It was argued that 'quick and dirty' ethnographies as well as 're-examination of previous studies' can prove useful in terms of 'sensitising' designers; whereas 'concurrent' and evaluative' ethnographies both contribute to challenging designers' assumptions as well as developing forms of evaluation. With 20-20 vision, this characterization of ethnography's relationship might seem over simplified, but it least set up the ground for some serious discussion of what the relationship between ethnography and design might look like, and a very significant literature was, and continues to be, produced.

There have already been a number of subsequent attempts to clarify and expand the relationship between ethnomethodology and design. Button and Dourish (1996, 1998) outlined a number of ethnomethodological investigations of technology in working settings, documenting how ethnomethodological work has traditionally approached system design through a concentration on detail; and presenting the means whereby ethnomethodology can "move from design critique to design practice" - what they term: 'technomethodology'. Their intent was to document, understand and then further develop the relationship between ethnomethodology and technological design since, "... as relevant parts of the design community have taken on board Suchman's arguments they have also taken on, perhaps unwittingly, an ethnomethodological influence". Nevertheless, differences in interest and approach between ethnomethodology and design have meant that the attempt to marry ethnomethodological understanding with design insights 'has been problematic'. Button and Dourish identify three particular ways in which ethnomethodology relates to design practice and IT research: learning from ethnomethodologists; learning from ethnomethodological accounts; and learning from ethnomethodology, 
whereby 'design does not take on board ethnomethodological analysis and insights, but takes on board the very study policy of ethnomethodology.“.

In advocating the perspective of 'technomethodology', Button and Dourish (1996) contrast ethnomethodology's well-known emphasis on documenting and analyzing the details, the particulars, of social interaction, with system design's emphasis on the creation and use of abstractions. But they claim that this is a rather short-sighted contrast since it ignores ethnomethodology's concern with 'generally operative social processes', grounded in a wide range of social interactions. They also point out that ethnomethodologists and system designers typically use generalisations in very different ways. However, the move towards technomethodology represents an attempt to align these different sensibilities: "technomethodology attempts to align system design not so much with the details of specific working practices, as with the details of the means by which such working practices arise and are constituted"(Button and Dourish 1996, p. 24). Crabtree (2004b) has further advanced the 'technomethodology' argument by advocating an approach which entails combining breaching experiments and perspicuous settings in an iterative process of innovation. While not hugely different from earlier attempt to introduce technology into (at least quasi-) real world settings (see von Hippel 2005), it does imply a distinctive view of what hybridity might mean. It is the exploration of the social and the technical that need to be linked or 'hybridized' and thereby we can move 'from design critique to design practice and the invention of the future.

Besides this concern with technomethodology, Hughes et al. (1992) recognized, ethnomethodologically informed ethnographic studies in CSCW and HCI as serving the design process in related but different ways, according to what kind of design issue they seek to address. These, as already suggested, might be roughly categorised as: tell me what is going on in this kind of setting - i.e., sensitising studies; tell me what to build studies - i.e., requirements; tell me what *not* to build - i.e., assumptions testing; give me some picture of what the technology in question can and cannot be expected to do, and why; tell me what people make of my design i.e., evaluative studies. This is not a typology or a taxonomy of the relationship between ethnomethodology and design - it is just a list. Nor is each item on the list especially distinctive from the others: sensitizing studies often produce results that test various design assumptions; evaluative studies, in particular formative evaluation studies can also prove to be 'sensitising' or can produce requirements. The categories are offered as a simple heuristic, a way of organizing ethnomethodological studies in order to consider their contribution to design and as such should not be regarded as mutually exclusive.

We have seen, then, how ethnographic enquiries which focus on the matters that ethnomethodologists have historically been interested in 'pay off' in various ways and at various times in and for the design process. The influence of these interventions can, we believe, be traced in a variety of subsequent studies. There can be little doubt that the interest in sequentiality that led Heath and Luff to mobilise video as a data collection method has been hugely influential. Equally, the more orthodoxly 
observational approach associated with, for instance, studies at Lancaster and elsewhere, studies which emphasised materiality, ecology, the practical use of artifacts, the 'what do I do next?' questions and the ordinary but elegant ways in which collaboration and coordination might take place have also affected both research and 'real world' design endeavours. Ethnographies which orient to this kind of analytic focus are now commonplace. We can see this in the way that the participatory design community has engaged productively with ethnographic strategies. One can, we suggest, trace the influence of this set of commitments in developments such as the 'design case study' approach advocated by Wulf et al. (2011). Although our German colleagues are not ethnomethodologists, their focus on a three-stage approach to design echoes some of what we have rehearsed above, albeit in an extended form. Broadly, they advocate pre-study, iterative design, and investigation into appropriation strategies as three interrelated strands.. There is no question that this long term, iterative, approach to design and its consequences represents a fruitful way of dealing with design problems beyond the immediate and local, whilst nevertheless paying due attention to it. Put simply, it entails a serious, largely ethnographic approach to practices and their transformation. Our concern here is only to demonstrate the way in which the notion of practice, the details of which are precisely what ethnomethodologists have been interested in, is central to such considerations.

\section{Ethnomethodological studies of work}

In this section we wish to briefly outline a number of studies that might be regarded as adopting the ethnomethodologically informed ethnographic approach. We cannot, for obvious reasons, rehearse all of the studies that claim, for good or ill, to explicitly embrace an ethnomethodological perspective, nor those which assert a commitment to some kind of ethnomethodologically informed ethnography. So we will choose four, beginning with the early days of European CSCW (circa 1989), where studies of organizational life, and more especially where the organizational features in question included technical (both in terms of knowledge deployed and technologies being used) elements, were relatively thin on the ground. Two studies in particular we see as groundbreaking. The first is the well-known study of the London Underground (1994) conducted by Christian Heath and Paul Luff, and the second, the air traffic control (ATC) studies associated with Lancaster university. The London Underground control room study, a study of "a complex multimedia environment in transition" was one of the first to use close video analysis to examine the way in which knowledge was shared between operatives by dint of glances, overhearing, 'surreptitious monitoring' and other subtle behaviours: “.., Control Room personnel have developed a subtle and complex body of practices for monitoring each other's conduct and coordinating a varied collection of tasks and activities. These practices appear to stand independently of particular personnel, and it is not unusual to witness individuals who have no previous experience working together, informally, implicitly, yet systematically coordinating their conduct." (Heath and Luff 1992, p. 73) In a 
nutshell, these practices are seamless, elegant and timely. The design of new technologies which might result in the redesign of work practices here, needs to address, as they point out, the shared nature of the artifacts in question: "... the Controller's activity in relation to the diagram has to be available to a co-participant, the activity has to be public. Thus, to facilitate individuals mutually to monitor their co-participants, technologies would have to support a 'seamlessness' between public and private activities." (Heath and Luff 1992: 91). ${ }^{2}$

In a similar vein, the Lancaster studies of ATC (Bentley et al. 1992, 1995) revealed that the mundane performance of various manual tasks, tasks that might relatively easily be automated, such as the use of the flight control strips, writing on them, manipulating them in the racks, and so on, helped to develop and maintain various forms of teamwork and ensured that the controller and the other members of the team were sufficiently 'geared into the work'. In short, the study explicated the ways in which aircraft control involves teamwork at the radar suite, rather than simply cognitive skills. While each member of the team had particular responsibilities, teamwork ensured that traffic flowed, maintained by informal monitoring and sharing of activities. Controllers, formally responsible for giving instructions to the aircraft concerning course, height, ascent and descent, and so on, also spent time coordinating the team, "arranging flight levels, discussing 'best' procedures to expedite the flow of traffic, sometime passing flight level changes to 'wings' to coordinate with adjacent sectors, and so on" (Bentley et al. 1992, p. 124). The point is that whilst individuals had their own tasks, the tasks required teamwork which was integral to its accomplishment, so that they could be adequately assembled within a working division of labour: "There was no one thing, or set of things, that manifested teamwork since it saturated the work itself - in the talk around the suite, in the activities performed, in the stories and anecdotes told, and more' (Bentley et al. 1992, p. 126). Not least, one of the insights of this study was the importance of the Flight Progress Strip which provided a composite picture of both the work being done and what might be anticipated: “...'You have got to have a complete picture of what should be in your sector and what should be in your sector is on those strips'... To the accomplished controller this display is an 'at a glance' means of showing the flow of traffic through the sector and its characteristics" (Bentley et al. 1992, p. 126). ${ }^{3}$

\footnotetext{
${ }^{2}$ We should also make reference to the range of studies that are collected in Heath and Luff 2000; Heath et al. 2000 and which are representative of close attention to sequentiality. Most of these studies (though not all) draw inspiration from ethnomethodology. In the latter work, Heath and Luff point to the particular importance of the sequentiality of 'talk in interaction', something that can readily be accomplished with the aid of video. They draw extensively on the conversation analytic variant of ethnomethodology but, regardless, they produced one of the earliest accounts of the uses of medical records, something that has occupied ethnographers of various stripes to a significant degree in recent years. Other work in the same collection looks at financial journalism, media spaces and architecture.

${ }^{3}$ Again, and briefly, the work at Lancaster University inspired a significant body of work, including work on retail financial services (Randall et al. 2005; Harper 1998).
} 
What emerged from all these studies was the recognition that mundane collaborative practices were critical to the smooth functioning of a technology- based system: "To the extent to which the work displays its apparent seamlessness, this is due to the smooth operation of the 'working division of labour' that is tacitly understood and trusted in and through the active involvement of team members in the 'doing' and the organisation of tasks".

Equally, lessons from both studies about the nature of design decisions could also usefully be drawn - concerning such things as automation and tailoring - which might well turn out to be inappropriate when developing cooperative systems. One particular study of relevance here was undertaken at Xerox Research Centre Europe (XRCE) in 2004. It arose because of an interest in Xerox at the time in reducing the Total Cost of Ownership (TCO) of Xerox devices. This interest had particularly come to centre around what were termed 'break-fix' costs - the cost of dealing with faults arising during the use of their devices. The articulation of cost differences in play at the time suggested a 'factors of ten' model whereby it was understood that dealing with a customer's problem on the telephone would cost ten times more than having them fix it by themselves using online resources. Likewise, having a service engineer go out to fix the device would cost at least ten times more than having it dealt with by a troubleshooter at a call centre over the telephone. There was therefore a strong imperative to move as many fault resolution events down the line to internet and telephone-based interactions as possible.

In the context of this concern ethnomethodologists working at XRCE conducted ethnographic studies of two primary bodies of practice: the work of telephone-based operatives providing a troubleshooting service over the telephone (termed 'Remote Call Assist') and the work of ordinary users trying to make use of an online knowledge base to resolve faults on their own. We cannot do justice here to a complex set of findings, but we focus here on some salient elements with a view to noting, again, how certain analytic foci come to the fore.

It was found that, with regard to the situated use of the knowledge base by ordinary customers in ordinary instances of device troubles, a number of different kinds of difficulties could arise. Many of these difficulties can be seen to hinge upon what the routine articulation of 'knowledge' might appropriately look like, depending on whether you are a service engineer or an ordinary user of a device. Relatedly, there was a classification issue, to do with terms used and their organization. It turned out that there was a conspicuous disjuncture between the technical renditions of problems around which the knowledge base was organized and the everyday commonsense understanding of problems one could see being displayed by users. It became clear that the knowledge base had been designed in terms of how an engineer might reason about a device, not someone possessed of only lay knowledge about printers and their operation. Again, this is but one study which carefully draws attention to the ways in which (in this case) both customers and operatives bring local, situated, rationales to their interactions. It is, however, a very good example of the kind of 
purchase detailed work can bring to processes of evaluation and design. ${ }^{4}$ So, the idea that computer systems should always, whenever possible, automate tedious and routine manual tasks or that interface designers should provide facilities for end-users to tailor interfaces to suit personal preferences were disputed by ethnographic observations. Ethnographic accounts, undertaken with some ultimate design purpose in mind, can act to challenge some of the implicit and explicit design assumptions of development teams, concerning, for example, the merits of tailoring or automation of tasks. That is, the relationship between ethnography and design is recognized as a complex and contingent matter.

Ethnographic studies of the kind associated with ethnomethodological tropes can also be used for evaluative purposes - as in our final example. While we do not subscribe to a model which separates evaluation from design, viewing (as do others) the process as iterative, there is some discussion and dispute over what might constitute an effective evaluation; when in the design cycle it should take place, how long any evaluation should last and the extent to which it should incorporate a range of aspects of the performance of the system that might fall outside any conventional notion of functional requirements. Grudin (1988), in a series of case studies, argues that the difficulty of evaluation, particularly of systems in use, is an important factor in understanding why CSCW systems so frequently fail to deliver their intended benefits, if indeed they are 'delivered' at all. Similarly Bannon (1996), suggests that the traditionally different and independent stages of design, use and evaluation should be regarded as being necessarily interwoven and that, since 'context of use' is so critical, evaluation should saturate the entire process from initial designs through to deployment.

A range of methodological techniques for performing evaluatiossns exists but ethnomethodological evaluations generally aim to examine systems in use, or as 'situated". The ethnographic evaluation documented here draws on research conducted as part of an ongoing and long-term engagement with the UK National Health

\footnotetext{
${ }^{4}$ A number of design propositions were made. These ideas included:

- Organisation of the knowledge base around a symptomatic taxonomy, with the structure reflecting symptoms and causes of problems, rather than a technical taxonomy based on faults.

- Providing the possibility of searching on either vernacular or technical terms or a mixture of both.

- Providing support for understanding the results of searches by giving technical terms lay descriptions and giving indications of what kinds of symptoms might accompany particular kinds of faults.

- Presenting search results in ways that would make clear how they were connected to the original search terms a customer had entered.

In passing, we might note that the work was the winner of the Software Innovation award in the Wall Street Journal's 2012 Technology Awards.

${ }^{5}$ And whilst clearly focusing on use, some ethnomethodological studies, (e.g. Crabtree's 'Design in the absence of practice' Crabtree 2004a; Twidale et al. 1994) have deployed evaluation techniques in a variety of new and interesting ways by subjecting new technologies and visions of the future to evaluation through the deployment of installations in real world settings. The notion of evaluation employed here is both loose and exploratory in character by treating new technical implementations as 'breaching experiments', or provocations, where novel technologies are confronted by actual circumstances of use.
} 
Service Breast Screening Programme (Hartswood and Procter 2000; Hartswood et al. 1998, 2002, 2003; Slack et al. 2007) using observational materials collected from studies of radiographers doing detection and diagnosis work, in conjunction with an expert computer aided detection system (CADe). The evaluation was especially interested in whether the CADe system could improve readers' performance. The studies oriented to the 'real time, real world' nature of diagnostic work, emphasizing the meaningful and practical human activity involved and thereby developing a baseline against which the new CADe technology could be assessed. The evaluation was based on a long-term ethnographic observation of a clinical trial of a CADe tool. Readers and the CADe tool were evaluated on their ability to spot cancers and whether the CADe tool impacted on the effectiveness and accuracy of readers. The practice of reading mammograms calls for readers to exercise a subtle combination of reasoning, knowledge and skills, a combination constitutive of readers' 'professional vision' - 'socially organized ways of seeing and understanding events that are answerable to the distinctive interests of a particular social group' (Goodwin 1994, p. 606). This involves using complex skills to find what may be faint and small features in the mammogram, and classify them appropriately.

The evaluation raised a variety of issues, including that there was a need for readers to reason about exactly why the machinery raised a prompt. Readers needed to 'account' for the prompt because it might be for a cancer (perhaps a subtle one) and so was something which readers were professionally bound to take note of. Interestingly, for a decision-aid, the CADe prompt did not make it any easier for a reader to reason about a film. It was a 'docile' prompt, unable to account for itself. The prompt required that readers deploy their professional vision to make sense of and make accountable what the machine was showing as a lesion or a calcification and requiring a decision to recall or not-recall. The evaluation also raised other issues concerned with the 'trustability' of the technology as the readers developed some sense of which prompts, in which areas of the mammogram, could be trusted and which could be reasonably dismissed.

\section{Conclusion and critique: what have the ethnomethodologists ever done for us?}

Our aim in this paper has been to trace the influence that ethnomethodology has had on the European CSCW community and the 'European fieldwork tradition'. In so doing, we have also argued that ethnomethdology itself has been appreciably developed during this time. We have suggested, for instance, that the influence of Wittgenstein, Winch and Schutz has been as significant as that of Garfinkel. Similarly, although ethnomethodological work was always, in principle, an empirical project, it was largely in the UK in the early 1990s that serious and prolonged empirical work was conducted in domains with high degrees of technical knowledge and technology use. We have further pointed to the way in which original, strong, claims to hybridity and unique adequacy have been necessarily watered down. 
Having said all this, in this final section we want to reconsider the ethnomethodologically informed ethnographic approach to $\mathrm{CSCW}$ in the light of a range of criticisms - most of which singularly fail to hit the mark. As Sharrock and Anderson noted some time ago, there have been few cogent criticisms of ethnomethodology (at least until recently, see Hammersley 2018) with most of them being either conceptually confused or just plain silly (Gellner 1975; Blackwell et al. 2017). The same goes for criticisms of EIE and 'workplace studies' and their relationship to Design - where there appear to be an equal number of confused responses and where the abiding question remains, "what are workplace studies for" (Plowman et al. 1995). The answer quickly appears that the ethnomethodologically informed ethnographic approach presents a number of possibilities without representing (or claiming to be) some kind of panacea for Design. Nevertheless, the value of ethnography in design remains a matter of controversy (cf. Anderson, 1994, 1997; Plowman et al. 1995). Perhaps we should only expect ethnography (or Ethnomethodology) to have some modest value or utility. In as much as any established position on the role of ethnography in CSCW design has emerged it resides in its simple but important ability to make visible the everyday nature of work. The role of ethnography as we have practised it, as EIE, has been mainly as some kind of informational input into design but this input can be of critical value insofar as it can advise the designer of actual practices of work and may clarify the role that actual practices play in the management of work, matters which may not normally be captured.

One critique of EIE and indeed all ethnographic approaches, that we would wish to address, arises from what has been termed the 'reflexive' turn in Sociology, whereby the tendency to treat ethnographic description as involving simple reproduction of the phenomena described is misleading and mythical, since description is always selective. Consequently, and following the 'reflexive turn', the relevances and values that structure any ethnographic description must be made explicit in order to prevent,. "the inscription of coherent ethnographic fictions" (Clifford 1986: 6). In this view the notion of a 'naturalist' ethnography that merely describes 'the facts of the matter' should instead be regarded as, "an insidious discursive strategy whose underlying purpose is to assert authority, dominate and maintain privilege" (Edles 2002, p. 151). The reaction against 'naturalistic ethnography' - 'postmodern ethnography' - involves a mixture of literary styles, fiction and poetry as part of 'faithfully' representing the lived qualities of the domain. This response may also be seen as a reflexive device, collapsing the distinction between 'object' and 'subject' thereby facilitating ways of ensuring that authors write themselves into the text. This 'self-reflexive turn' takes a number of guises but often appears to take a confessional form whereby researchers document their own actions, attitudes and prejudices and consider how this might have impacted on the setting they investigate. The result of this move, however, has been a shift away from a careful concern with the research setting and its members to a focus on the researcher and the research act itself - and the subsequent endless 'navel gazing', 'confessional tales' and some feeble attempts at poetry. This postmodern, constructivist challenge to naturalistic or 'naïve' ethnography, and the subsequent demands for 
'reflexive' ethnography, with a more self-critical and sceptical orientation, has been challenged by those who conduct ethnomethodologically informed ethnographies (Sharrock 1995; Slack 2000). The ethnomethodological endeavour lies in describing how members (not researchers, or sociologists) manage to produce and recognise contextually relevant structures of social action.

To conclude, the warrant for ethnomethodologically informed ethnography is that of 'probativeness' or 'faithfulness to the phenomena' - that the description of the situated organisation of that activity in its detail makes that real worldly activity mutually intelligible. When used from an ethnomethodological stance ethnographic work involves a renewed and unprejudiced (and difficult) look at the phenomena that have frequently become obscured beneath layers of theoretical abstraction and speculation. It sets out, as Garfinkel (1967) puts it; "to treat practical activities, practical circumstances, and practical sociological reasonings as topics of empirical study, and by paying to the most commonplace activities of daily life the attention usually accorded extraordinary events, seeks to learn about them as phenomena in their own right" (Garfinkel 1967) The aim for the ethnomethodologically informed ethnographer is to be led by the phenomena, to observe and describe the phenomena of 'everyday, mundane working life' independently of any preconceptions of conventional or fashionable sociological theories and methods, taking an 'unmotivated' approach to the activities, looking just to see what people are doing, rather than seeking to identify things which might be 'sociologically interesting' or 'theoretically relevant' or 'counterintuitive'. This approach recognises, and strongly resists, the temptation when studying others' lives to read things into them (and thereby 'make stuff up') since (perhaps fortunately) the social world is not always organised in ways that analysts and researchers want or presume. It is not for the investigator to decide what things are, what matters, what is important, or trivial, but to ascertain how things are judged in that way by those who are doing them, to examine the familiarity with and understanding of these matters possessed by those who must work and live with them. With ethnomethodologically informed ethnography, attention is focused on the actual 'doing' of work: work in the raw, how it is done in actual practice, as opposed to work in some idealised or theorised form - and it is this, and the range of empirical studies produced, that we believe is, or eventually becomes, important to design and designers of various kinds, and represents a good part of ethnomethodologically informed ethnography's contribution to the European fieldwork tradition.

\section{Acknowledgements}

Thanks to Andy Crabtree and Graham Button for comments and observations on earlier versions of this work, although any faults or failures in the argument are, unfortunately, ours. We also thank various anonymous reviewers for some insightful comments and clarifications; and we forgive them for the removal of all our 'jokes' and sarcastic asides. 
Open Access This article is licensed under a Creative Commons Attribution 4.0 International License, which permits use, sharing, adaptation, distribution and reproduction in any medium or format, as long as you give appropriate credit to the original author(s) and the source, provide a link to the Creative Commons licence, and indicate if changes were made. The images or other third party material in this article are included in the article's Creative Commons licence, unless indicated otherwise in a credit line to the material. If material is not included in the article's Creative Commons licence and your intended use is not permitted by statutory regulation or exceeds the permitted use, you will need to obtain permission directly from the copyright holder. To view a copy of this licence, visit http:// creativecommons.org/licenses/by/4.0/.

\section{References}

Anderson, Robert J. (1994). Representations and requirements: the value of ethnography in system design. Human-computer interaction, Vol. 9, No. 2, pp.151-182.

Anderson, Robert J. (1997). Work, ethnography and systems design. In A. Kent and J. G. Williams (eds): The Encyclopedia of Microcomputing, vol. 20. New York: Marcel Dekker, pp. 159-183.

Bannon, Liam J. (1996). Use, design and evaluation: steps towards an integration. In Human Factors in Information Technology. Vol. 12, pp. 423-443.

Bannon, Liam; Kjeld Schmidt; and Ina Wagner (2011). "Lest we forget." In ECSCW 2011: Proceedings of the 12th European Conference on Computer Supported Cooperative Work, 24-28 September 2011, Aarhus Denmark, London: Springer, pp. 213-232.

Benson, Doug; and John Hughes (1991). Method: evidence and inference-evidence and inference for ethnomethodology. in G. Button (ed.): Ethnomethodology and the human sciences, Cambridge: Cambridge University Press, pp.109-136.

Bentley, Richard; John A. Hughes; Dave Randall; Tom Rodden; Pete Sawyer; Dan Shapiro; and Ian Sommerville (1992). Ethnographically-informed systems design for air traffic control. In CSCW 1992: Proceedings of the 1992 ACM conference on Computer-supported cooperative work 31 October - 4 November 1992, Toronto. New York: ACM Press. pp. 123-129.

Bentley, Richard; John A Hughes; David Randall; and Dan Z. Shapiro (1995). Technological support for decision making in a safety critical environment. Safety Science. Vol 19, No. 2-3, pp.149-156.

Berger, Peter L. (2002). Whatever happened to Sociology? (Opinion). First Things: A Monthly Journal of Religion and Public Life, pp.27-30.

Blackwell, Alan F; Mark Blythe; and Jofish Kaye (2017). Undisciplined disciples: everything you always wanted to know about ethnomethodology but were afraid to ask Yoda. Personal and Ubiquitous Computing, Vol. 21, No.3, pp. 571-592.

Brown, Barry; and Matthew Chalmers (2003). Tourism and mobile technology. In ECSCW 2003: Proceedings of the European Conference on Computer Supported Cooperative Work, 14-18 September 2003, Helsinki, Finland. Dordrecht: Springer, pp. 335-354.

Brown, Barry; and Nicola Green (eds) (2012). Wireless world: Social and interactional aspects of the mobile age. Springer Science \& Business Media.

Burman, Erica (1997). Minding the gap: Positivism, psychology, and the politics of qualitative methods. Journal of Social Issues, Vol. 53, No. 4, pp.785-801.

Button, Graham (2012). What does 'work' mean in 'ethnomethodological studies of work?': Its ubiquitous relevance for systems design to support action and interaction. Design Studies. Vol. 33, No.6, pp.673-684. 
Button, Graham; and Paul Dourish (1996) "Technomethodology: paradoxes and possibilities." In CHI 1996: Proceedings of the SIGCHI conference on Human factors in computing systems, 14-18 April 1996, Vancouver, Canada. ACM Press, pp. 19-26.

Button, Graham; Andy Crabtree; Mark Rouncefield; and Peter Tolmie (2015). Deconstructing ethnography. Towards a social methodology for ubiquitous computing and interactive systems design. Dordrecht: Springer.

Comic Deliverable D2.1, (Undated), Informing CSCW System Requirements, COMIC Working Paper, Lancaster: Department of Sociology.

Cooper, Geoff (1991). Context and its Representation, Interacting with Computers, Vol. 3, No. 3, pp. 243-252

Coulter, Jeff, (1991). Cognition: cognition in an ethnomethodological mode. In Button, Graham (1991) Ethnomethodology and the Human Sciences, Cambridge University Press, pp.176-195.

Cooper, Geoff; Christine Hine; Janet Rachel; and Steve Woolgar (1995). Ethnography and humancomputer interaction. in Peter J. Thomas (ed): The Social and Interactional Dimensions of Human Computer Interfaces, Cambridge: Cambridge University Press. pp.11-36.

Crabtree, Andy (2001). Wild Sociology: Ethnography and Design. Unpublished PhD Thesis. Department of Sociology. Lancaster University.

Crabtree, Andy (2004a). Design in the absence of practice: breaching experiments. In: DIS 2004: Proceedings of the 5th Conference on Designing Interactive Systems: Processes, Practices, Methods, and Techniques. 1-4 August 2004, Cambridge, Mass. New York: ACM Press, pp. 59-68.

Crabtree, Andy (2004b). Taking technomethodology seriously: hybrid change in the ethnomethodology- design relationship. European Journal of Information Systems, Vol, 13, No. 3, pp.195-209.

Crabtree, Andy; Tom Rodden; Peter Tolmie and Graham Button (2009), Ethnography considered harmful. In . ACM Press pp. 879-888.

Dourish, Paul (2006). Implications for design. In CHI 2006: Proceedings of the SIGCHI conference on Human Factors in computing systems. 24-27 April 2006, Montreal, Canada. ACM Press. pp. 541-550.

Dourish, Paul (2007). Responsibilities and implications: further thoughts on ethnography and design. In Proceedings of the 2007 conference on Designing for User eXperiences. ACM Press. p. 2-16.

Dourish, Paul; and Genevieve Bell (2011). Divining a digital future: Mess and mythology in ubiquitous computing. MIT Press.

Dourish, Paul; and Graham Button (1998). On "technomethodology": Foundational relationships between ethnomethodology and system design. Human-computer interaction, Vol. 13, No. 4, pp. 395-432

Edles, Laura (2002). Cultural Sociology in Practice. Oxford: Blackwell.

Ferrell, Jeff (2009). Kill Method; A Provocation. Journal of Theoretical and Philosophical Criminology, Vol 1, No. 1.

Garfinkel, Harold (1964). Studies of the routine grounds of everyday activities. Social Problems. Vol. 11: pp. $225-250$.

Garfinkel, Harold (1967). Studies in ethnomethodology. Englewood Cliffs, NJ: Prentice Hall. 2nd edn, Paradigm Publishers.

Garfinkel, Harold (2002). Ethnomethodology's program: Working out Durkheim's aphorism. Boulder, CO: Rowman \& Littlefield.

Garfinkel, Harold ([1948] 2006). Seeing sociologically. Boulder, CO: Paradigm Publishers.

Garfinkel, Harold; and D L Weider (1992) Evidence for locally produced, naturally accountable phenomena of order, logic, reason, meaning, method, etc. in Watson G, and R. Seiler. (eds): Text in Context: Contributions to ethnomethodology, London: Sage, pp.175-206.

Gellner, Ernest (1975). Ethnomethodology: the re-enchantment industry or the Californian way of subjectivity. Philosophy of the Social Sciences, Vol. 5, No. 3, pp. 431-450. 
Gilbreth, Lillian Moller (1927). Home-maker and her job.. New York: D. Appleton and Company. Goodwin, Charles (1994). Professional vision. American Anthropologist, Vol. 96, No.3 pp. 606-633. Grudin, Jonathan (1988). Why CSCW applications fail: problems in the design and evaluation of organizational interfaces. In CSCW 1988: Proceedings of the 1988 ACM conference on Computersupported cooperative work, 26-28 September 1988, Portland, Oregon, USA. ACM Press. pp. 8593.

Hacker, Peter M. (2012). The relevance of Wittgenstein's Philosophy of Psychology to the Psychological Sciences. Deutsches Jahrbuch Philosophie, Vol. 3, pp. 205-223.

Hammersley, Martin (2018). The radicalism of ethnomethodology: An assessment of sources and principles. Manchester: Manchester University Press.

Harper, Richard H. R (1998). Inside the IMF: an ethnography of documents, technology and organisational action. Routledge.

Harper, Richard H. R (2016). From I-awareness to we-awareness in CSCW: A review essay. Computer Supported Cooperative Work (CSCW), Vo. 25, No. 4-5, pp. 295-301.

Harper, Richard H. R; and David Randall (1992). Rogues in the air: an ethnomethodology of 'conflict'in socially organised airspace. Cambridge, MA: Rank Xerox Ltd.

Harré, Rom (2017). Wittgenstein and psychology: A practical guide. Routledge.

Hartswood, Mark; Rob Procter; and L. Williams, (1998). Prompting in mammography: Computeraided Detection or Computer-aided Diagnosis. Proceedings of Medical Image Understanding and Analysis, MIUA, No. 98, pp.6-7.

Hartswood, Mark; and Rob Procter, (2000). Computer-aided mammography: a case study of coping with fallibility in a skilled decision-making task. Topics in Health Information Management, Vol. 20, No.4, pp.38-54.

Hartswood, Mark; Rob Procter; Mark Rouncefield; and Roger Slack (2002). Performance management in breast screening: A case study of professional vision. Cognition, Technology \& Work, Vol. 4, No.2, pp. 91-100.

Hartswood, Mark; Rob Procter; Mark Rouncefield; Roger Slack; James Soutter; and Alex Voss (2003). Repairing'the Machine: A Case Study of the Evaluation of Computer-Aided Detection Tools in Breast Screening. In K. Kuutti, et al. (eds): ECSCW 2003: Proceedings of the Eighth European Conference on Computer Supported Cooperative Work, 14-18 September 2003, Helsinki, Finland. Dordrecht: Kluwer Academic Publishers, pp. 375-394.

Slack, Roger; Mark Hartswood; Rob Procter; and Mark Rouncefield (2007). Cultures of reading: On professional vision and the lived work of mammography. In Hester Steve and Dave Francis (eds): Orders of Ordinary Action: Respecifying Sociological Knowledge. Burlington, VT: Ashgate, pp. $175-194$.

Heath, Christian; and Paul Luff (1992). Collaboration and control Crisis management and multimedia technology in London Underground Line Control Rooms. Computer Supported Cooperative Work (CSCW), Vol 1, No.1-2, pp. 69-94.

Heath, Christian; and Paul Luff (2000). Technology in Action. Cambridge University Press.

Heath, Christian; Hubert Knoblauch; and Paul Luff (2000). Technology and social interaction: the emergence of 'workplace studies'. The British Journal of Sociology. Vol. 51, no. 2, pp. 299-320.

Hughes, John A; David Randall; and Dan Shapiro (1992). Faltering from ethnography to design. In CSCW 1992: Proceedings of the 1992 ACM conference on Computer-supported Cooperative Work, 1-4 November 1992. Totonto, Canada. ACM Press. pp. 115-122.

Hughes, John; Val King; Tom Rodden and Hans Andersen (1994). Moving out from the control room: ethnography in system design. In J. B. Smith; F. D. Smith; and T. W. Malone (eds): CSCW'94: Proceedings of the Conference on Computer-Supported Cooperative Work, 24-26 October 1994, Chapel Hill, North Carolina. New York: ACM Press, pp. 429-439

Jones, Matthew R; and Helena Karsten (2008). Giddens's structuration theory and information systems research. MIS quarterly, Vol. 32, No.1, pp.127-157. 
Kaptelinin, Victor; and Bonnie A Nardi (2006). Acting with technology: Activity theory and interaction design. MIT Press.

Latour, Bruno (2006). Reassembling the social: An introduction to actor-network-theory. Oxford University Press.

Luff, Paul; Jon Hindmarsh; and Christian Heath. eds (2000). Workplace studies: Recovering work practice and informing system design. Cambridge University Press.

Lynch, Michael (1985). Art and Artifact in Laboratory Science: A study of shop work and shop talk in a research laboratory. London. Routledge and Kegan Paul.

Lynch, Michael (1999). Silence in Context: Ethnomethodology and Social Theory. Human Studies 22 pp. 211-233.

Lynch, Michael (2000). "Against reflexivity as an academic virtue and source of privileged knowledge." Theory, Culture \& Society. Vol. 17, No. 3. pp. 26-54.

Lynch, Mike (2006). Cognitive activities without cognition? Ethnomethodological investigations of selected 'cognitive'topics. Discourse Studies, Vol. 8, No.1, pp.95-104.

Macbeth, Douglas (2001). "On "reflexivity" in qualitative research: Two readings, and a third." Qualitative Inquiry. Vol.7, No. 1. pp. 35-68.

Malinowski, Bronislav (2013). Argonauts of the Western Pacific: An Account of Native Enterprise and Adventure in the Archipelagoes of Melanesian New Guinea [1922/1994]. Routledge.

Plowman, Lydia; Yvonne Rogers; and Magnus Ramage (1995). What are workplace studies for?. In ECSCW'95: Proceedings of the Fourth European Conference on Computer-Supported Cooperative Work, Stockholm, September 11-15. Dordrecht: Kluwer, pp. 309-324.

Radcliffe-Brown, Alfred R. (1922/2013). The Andaman islanders. Cambridge University Press.

Randall, David (2018). Investigation and Design, in Wulf et al. Socio-Informatics. Oxford University Press, pp. 221-242

Randall, David; Jon O'Brien; Mark Rouncefield; and John.A Hughes (1996). Organisational memory and CSCW: supporting the 'Mavis Phenomenon'. In OzCHI 1996: Proceedings Sixth Australian Conference on Computer-Human Interaction, 24-27 November, Hamilton, New Zealand. IEEE. pp. 26-33.

Randall, David; John Hughes; Jon O'Brien; Mark Rouncefield; and Peter Tolmie (2001). 'Memories are made of this': explicating organisational knowledge and memory. European Journal of Information Systems, Vol. 10 No. 2, pp.113-121.

Randall, David; Tom Rodden; Mark Rouncefield; and Ian Sommerville (2002). Remembrance of designs past: legacy data, organisational memory and distributed design. In Systems Engineering for Business Process Change: New Directions. London: Springer. pp. 317-330.

Randall, David; Richard Harper; and Mark Rouncefield (2005),. Fieldwork and Ethnography: A perspective from CSCW. In EPIC 2005: Ethnographic Praxis in Industry Conference Proceedings, Redmond, USA. Vol. 2005, No. 1. Oxford, UK: Blackwell Publishing Ltd. pp. 81-99.

Randall, David; Richard Harper; and Mark Rouncefield (2007). Fieldwork for design: theory and practice. London: Springer Science \& Business Media.

Rogers, Yvonne; and Judi Ellis (1994). Distributed cognition: an alternative framework for analysing and explaining collaborative working. Journal of information technology, Vol. 9, No. 2, pp.119-128.

Rouncefield, Mark; and Peter Tolmie (eds) (2016). Ethnomethodology at work. London: Routledge.

Sacks, Harvey (1992). Lectures on conversation. 2 vols. Edited by Gail Jefferson with introductions by Emanuel A. Schegloff. Oxford: Basil Blackwell

Schmidt, Kjeld (2014). The concept of 'practice': What's the point?. In COOP 2014: Proceedings of the 11th International Conference on the Design of Cooperative Systems, 27-30 May 2014, Nice. France. Springer. pp. 427-444..

Schutz, Alfred (1967). The phenomenology of the social world. Northwestern University Press.

Sharrock, Wes (1995). Issues in Ethnography: Ethnomethodology and Constructionism. COMIC document MAN-2-4. Manchester University. 
Sharrock, Wes; and Robert Anderson (1982). The demise of the native, Human Studies, Vol.15, No. 2, pp. 119-135.

Sharrock, Wes; and Robert Anderson (1986). The Ethnomethodologists, Chichester: Ellis Harwood

Sharrock, Wes; and Robert J Anderson (1994). "The user as a scenic feature of the design space", in Design Studies. Vol. 15 No.1, pp. 5-18.

Sharrock, Wes; and David Randall (2004). Ethnography, ethnomethodology and the problem of generalisation in design. European journal of information systems, Vol. 13, No. 3, pp.186-194.

Sharrock, Wes; and David Randall (2016). The Sociologist as Movie Critic. In Rouncefield, Mark and Peter Tolmie (eds), Ethnomethodology at Work Routledge. pp. 27-44.

Slack, Roger (2000). Reflexivity or sociological practice: A reply to May. Sociological Research Online, Vol. 5, No. 1, pp. 27-31.

Slack, Roger; Mark Hartswood; Rob Procter; and Mark Rouncefield (2007). Cultures of reading: On professional vision and the lived work of mammography. In Hester Steve and Dave Francis (eds): Orders of Ordinary Action: Respecifying Sociological Knowledge. Burlington, VT: Ashgate, pp. 175-194.

Sommerville, Ian; Tom Rodden,; Peter Sawyer; and Richard Bentley (1992). Sociologists can be surprisingly useful in interactive systems design. People and computers, pp. 341-341.

Suchman, Lucy (1987). Plans and Situated Action: The Problem of Human-Machine Communication. Cambridge University Press.

Tolmie, Peter; and Mark Rouncefield (eds) (2016). Ethnomethodology at play. London: Routledge.

Twidale, Michael; David Randall; and Richard Bentley (1994) Situated evaluation for cooperative systems. In CSCW 1994: Proceedings of the 1994 ACM conference on Computer supported cooperative work, 22-26 October 1994, Chapel Hill, North Carolina, USA. ACM Press. pp. 441-452.

Vicente Kim J. (1999). Cognitive work analysis: Toward safe, productive, and healthy computerbased work. CRC Press,

Von Hippel, Eric (2005). Democratizing innovation. MIT Press,

Watson, Rodney (2005). Reflexivity, description and the analysis of social settings. Ciências Sociais Unisinos. Vol. 41, No. 1 pp. 1-6.

Weilenmann, Alexandra (2001). Negotiating use: Making sense of mobile technology. Personal and Ubiquitous Computing Vol. 5, no. 2, pp. 137-145.

Winch, Peter (1964). Understanding a primitive society. American Philosophical Quarterly. Vol. 1, No. 4, pp. 307-324.

Winch, Peter (2002). The idea of a social science: And its relation to philosophy. London: Routledge.

Wittgenstein, Ludwig (2007). Wittgenstein: Lectures and Conversations on Aesthetics, Psychology and Religious Belief. University of California Press.

Wulf, Volker; Markus Rohde; Volkmar Pipek; and Gunnar Stevens (2011). Engaging with practices: design case studies as a research framework in CSCW. In CSCW 2011: Proceedings of the ACM 2011 conference on Computer Supported Cooperative Work, 19-23, 2011, Hangzhou, China. ACM Press. pp. 505-512.

Publisher's Note Springer Nature remains neutral with regard to jurisdictional claims in published maps and institutional affiliations. 